Fluoxetine Supplement; 'Journal', September 1988, 153

DeAR SirS

Drs Kerwin \& Lewis seem to have gone to some lengths to have their views published concerning the above Supplement (Psychiatric Bulletin, October $1989,13,565)$. While they have no doubt been motivated by concern for us "unwary readers", I find their attitude somewhat patronising.

Most psychiatrists are selective about what they read. The Supplement in question was sponsored by a drug company. Ten of the 15 articles concerned a product of that company, four of them were written entirely by employees of that company and they were part authors in another two. I am sure that the reaction of most psychiatrists to such a publication would be to file it away unread. This would explain the editor's comment that three months after the publication of the Supplement, only three readers had expressed disapproval with no additional matter of substance raised since (Psychiatric Bulletin, October 1989, 13, 566).

A further Supplement was issued with the October edition of the Journal. This was sponsored by another drug company. Six of the articles concerned a product of that company. Two of them were written entirely by employees of that company and they were part authors of another two. I have already filed my copy away. Any doubts that I might have had about the wisdom of this action were dispelled when I read a paper "subjected to a stringent peer-review process and detailed scientific editing" in October's Journal (Tiller et al, 1989). This paper showed that the drug in question had no antidepressant effect when compared to diazepam. I am sure that many of the Journal's 12000 subscribers have done the same.

Psychiatric Unit

RHODRI HUws

Northern General Hospital

Sheffield S5 $7 A U$

Reference

Tiller, J., Schwetzer, I., Maguire, K. \& Davies, B. (1989) Is diazepam an antidepressant? British Journal of Psychiatry, 155, 483-489.

\section{Performance indicators in child and adolescent psychiatry}

\section{DeAR SIRS}

Following recent pressure for greater 'audit' activity a questionnaire on the completion of the 'Körner' information returns was sent to all members of the South East Thames Regional Child Psychiatry Committee. Replies were received from 18 consult- ants from all 15 District Health Authorities and from the Special Health Authority.

The District results are summarised below:

Q1. Do you (or your secretary) complete information returns for your District Information Department?

All respondents complete returns, but there were often two types, and uncertainty as to what their Information Department passed on.

\section{Q2. How do you count a 'case'?}

Seven counted a 'case' as each child specifically referred (could be more than one child per family). Two counted one case per referral letter. Four counted separately the child as one case and the number of family members seen. One counted family members and/or professionals seen. One counted for new cases the index child only, for later attendances 'all those involved'. One counted by index child whether the child, other family members or professionals were seen. One counted all family members seen. One counted all family members and telephone consultations.

Q3. Do you confine the numbers to those actually seen by a doctor?

In 13 cases numbers were exclusively those seen by doctors; in the five others other professionals were included.

Q4. Would you include one-way screen viewing?

Nine respondents do not include one-way screen viewing, five respondents do, and for four it was inapplicable.

Q5. If you count more than one person per case how do you code non-attendances?

This did not apply for 11. Other replies were: however many people asked/anticipated who have not attended (3), one per family (1), one per 'case' (2), two per 'case' (1).

Q6. How do you estimate clinics held/cancelled?

Two did not know and one does not make this return. All the other answers were different but the main types of situation seemed to be that in a 'dedicated' department whenever it was open could be counted as a session; two hospitals had discrete clinics (but one ignored patients being seen elsewhere); one department had agreed 'notional' clinics; three appeared to be the consultant's entire number of sessions. 'Cancellation' definitions included: 'Secretary records any part of the day when cases are not seen as cancelled clinics'; 'by consultant's presence/ absence'; 'if no medical staff at all present and bank holidays'; 'lack of Körner information that day'.

Q7. Do you code under 'GP letters' just that, or other referrals also?

Five returned GP letters only; one all GP referrals, (i.e. including telephone referrals); one all 'health' 